\title{
David Minkowski, service producer
}

David Minkowski is the head of production for Stillking Films in Prague, where he has worked on projects like The Bourne Identity (2002) and Casino Royale (2006). The company, founded more than two decades ago, played an early and integral role in attracting large-scale feature film and television productions to the region. Minkowski describes how the increased competition among different territories to attract foreign producers has increased the complexities of his job, while also affecting the fortunes of Prague as a production hub.

At the height of the production craze in the late 1990s and early 2000s, Stillking was a major player. Tell us about those early years when you found yourself servicing back-to-back features.

It was amazing. This was before incentives; producers were attracted to Prague because it was gorgeous and cheap. They were interested in it for its creative potential, for the looks it provided, and they were writing scripts for Prague. From 2000 to 2008, it was nonstop work; the industry just exploded here. Then Budapest got an incentive. London got an incentive. Berlin got an incentive. We saw other locations start to emerge, and work in Prague started to decline.

What was the nature of your job in the early years?

Our objective was to help people in a foreign land that was alien to them. In the 1990s, this place was more alien, more foreign, to Americans. Fewer people spoke English. Fewer services existed. You had to be much more clever about what 
vendors you used. It wasn't just a phone call to get this or that crane or camera. You had to have your wits about you.

It was such a wild ride then. Suddenly the big names were coming to Prague. The amount of talent we hosted here! Away from home and the prying eyes of the studio, they were so much more open and accessible. You could sit down with Jerry Bruckheimer or Matt Damon or Barbara Broccoli. You could take them out to dinner. You could hang out with them. You could learn from them. It was a really, really great time.

As we started amassing more credits, making more relationships, and establishing our reputation, our role also evolved-we became the line producers, essentially overseeing all below-the-line aspects. We hire crew. We manage crew. We supervise locations. We navigate local bureaucracy, like explaining labor laws, child work permits, that kind of stuff. Even though the industry has evolved, it's still different working in Eastern Europe than in the States.

\section{What sorts of issues did you have to manage?}

A lot of clarification, whether it was language or different assumptions lost in translation. A producer friend of mine is fond of saying, "It doesn't matter where you shoot. It's all about the concept of time. What does 'I need it now' mean?" And that can vary across cultures. For example, there's this great story from a TV movie shoot my friend did in the early 1990s in Lithuania. It's the day before the first day of the shoot. The producer wants to make sure they have the right film stock on the camera truck to start filming the next day. The camera assistant says, "No problem! It's all covered!" The producer isn't convinced, so he says, "Okay. Show me. Let's go to the truck so you can show me the film stock that you think is enough for the day." They walk over to the truck and there's only one roll of film there! One thousand feet! Because for them [the crew], in the Soviet days, they would never shoot more than a thousand feet in a single day. A single roll might last for days. They would film a single shot and then say, "That's a wrap. We'll come back tomorrow." They had all the time in the world. Our job was to make sure those misunderstandings don't happen.

When we did Bad Company (2002) with Anthony Hopkins, I had probably seven or eight translators. A translator at camera. A translator at grip. Three translators at makeup. You had to have them. Today, we don't have any. Zero. Everybody speaks English, even the electricians. It's just the common language of film production now.

\section{Name one of the most critical services you provide.}

Finding locations remains an integral function of what we do. It's the first thing that happens when producers are considering Prague. They need a location scout. 
They also ask lots of questions: "Can we do this? Can we do that? Can we put snow down on the street?"

Our location managers are responsible for facilitating these requests. They'll advise the producer: yes, this is possible, or no, that's impossible. Oftentimes they'll think something is impossible simply because it's inconceivable to them that the authorities would ever grant permission for whatever request. Of course, producers don't take no for an answer. They'll come to me and say, "You need to make this happen. We need to get snow on the ground!"

The Bourne Identity is a great example. We filmed all the Zurich winter scenes in Prague when there wasn't snow on the ground. We had to fake it. There was this huge shoot in the center of Prague. We had to rent trams and paint them to look like Zurich trams. We needed to get snow on these parapets that were two stories high, which you can only do with cherry pickers [elevated work platforms]. We had cherry pickers running up and down the street blowing snow all over the place, and then when we were finished shooting, it all had to get cleaned up. That whole process is inconceivable for a location manager who hasn't done it before.

A similar issue popped up with the film we're doing now, Ridley Scott's Child 44 (2015). The film is set in Moscow in the 1950s. We needed a metro station, and of course the only one that worked for our needs also happened to be the busiest metro station in Prague. No one had ever shot there before unless it was a quick scene they could schedule between midnight and three in the morning when the station is closed. Our schedule called for two twelve-hour days of shooting in a metro station. The location manager said, no, it's impossible. We can't do it. Why? Because we've never done it before! They'll never let us! So I got involved. I called the mayor of Prague and explained what we needed. By the end of the day, we received this great letter from the mayor saying Ridley Scott is a great producer and the city wants to help. They closed the station for two full days and rerouted the metro traffic on city buses. Of course we had to pay for it, but the cost was relatively low compared to doing something similar in London or New York.

This is why it's important for me to keep my crews together and work with the same people. It helps them realize what's possible-that anything is possible, really. Let's say "yes" and then figure out how to get it done.

With respect to the key positions on a production, describe the breakdown between local versus foreign crew.

It varies from movie to movie. Television brings fewer people because there are more budget constraints. The more money you have, the more people you bring with you. Forget about above-the-line; they always come with the production, and they pick up local extras. In terms of crew, they always bring the DP [director of 
photography]. They always bring the first assistant director. They always bring a costume designer. They almost always bring a production designer. They almost always bring their own makeup and hair. After that, it's about the budget. If they have money, they'll bring a set decorator and a prop master. They'll bring a camera operator. They'll always bring their own accountant.

We are very strong in technical areas. Grip. Electric. Sound. The production office also is strong.

\section{How has the local crew base changed during your time in the business?}

When I started working here in 1995, I was working with two different generations. There was the older generation that had been working on movies for ten or twenty years, mostly during Communist times. They were thirty, forty, and fifty years old and very difficult to work with. They didn't speak English. They had bad habits-they'd go get drunk at lunch. They weren't trained to work in the American style. But you needed them because they had the experience. Then there was the younger generation; the people I brought in. They didn't have any experience but they spoke English and they were young and eager. They were willing to work sixteen- to eighteen-hour days and learn as they went.

In 1995, they were in their early twenties. I've watched them grow up. I've watched them get married, have kids, and pay mortgages. I've watched their whole lives transform from this process; they had no clue what they were getting into when they started. The industry transformed them. Now we're reaching a point where they're in their late thirties and forties and they don't want to do it anymore. They'll be fifty soon. They'll want to retire. I have to start the process all over again. I'm constantly looking out for new young people who want to get into the business.

\section{How often do you interface with public authorities?}

All the time. We did a string of action pictures in the 2000s. That's what we became known for. I negotiated a lot of permits to shoot car chases and shootouts in the center of Prague. Filmmakers wanted all of this intense action against the beautiful backdrop of the city. I was rerouting trams, closing traffic, and getting permission for gunfire in the middle of the night. Each film we do always presents a new challenge, something bigger and more complicated than the last shoot. In the early days, that actually worked to our advantage. Public authorities were always a little bit dumbfounded by the things we wanted to do. You want to close down traffic on the river to film a scene that's supposed to take place on the Thames in front of the British Parliament? Um, sure? Maybe they just wanted to see if we could actually do it. 
Today, they care more about the residents. They are much more concerned about the neighborhood and what disruptions we'll cause, so they're more cautious. Of course, if there's a chance to associate the city with a very big movie, things are much easier. Casino Royale (2006) is a perfect example. Everybody knows James Bond. Everybody loves James Bond. The series had always been filmed in London. They would do some second-unit location shooting in these exotic locales to make it look like they were there, but 85 percent of what you saw on screen had always been done in London. However, Casino Royale was the first Bond movie based primarily outside of London-we shot about 60 percent of the movie here. Remember the big airport sequence toward the beginning when a terrorist is going to blow up an airplane? We called up [Prague's Vaclav Havel Airport] and explained what we wanted to do and we were able to shoot on the tarmac, airside, throughout the whole airport, gunfire, fire trucks, police, everything! We had phenomenal cooperation and it was because they wanted to be involved with a James Bond movie. If I had wanted to close down the main airport for a sequence in a movie with no famous names? It may have been possible, but it would have been much more difficult.

\section{How do you secure work?}

Producers will send you a script. They want to see locations and a budget. You send them to a website with pictures you've loaded based on the script. It's important for them to visualize the locations. You want them to see their movie here. If they say, "Yes, this works," then you do a budget and they compare it to other locations they're considering.

If you're dealing with an A-list director, where does he or she really want to go? John Moore scouted four or five cities for A Good Day to Die Hard (2013). At the end of the day, he wanted to make the film in Budapest. The same holds true for big-name actors. I wanted to make The Monuments Men (2014) here; they were interested for a while. But they selected Berlin pretty early in the process. I don't think it was rebate-related. I think they had George Clooney and Matt Damon and other major actors, and they wanted somewhere comfy and cozy.

\section{How do producers compare location costs?}

It's the Big Mac test. How much is a Big Mac in Budapest? How much is a Big $\mathrm{Mac}$ in London? I can tell you what a grip costs in Prague, and what a grip costs in London. A grip in Prague is 100 euro a day. In London it's closer to 300 euro a day, plus a 35 percent fringe [taxes and additional employer fees]. Right there, you can multiply that by $150 \mathrm{crew}$ positions. For Prague, you'll likely have more 
travel and lodging costs because you bring more people with you. You compare big chunks, like extras. Extras are always a major part of a budget. Are you building sets? Construction is another easy category. A carpenter in Prague will cost you about 75 percent less than it does in London. Your materials, however, are about the same. A piece of wood costs the same here as it does in London because it all comes from Sweden.

Line producers will often do comparisons for a project. They'll literally call five different cities to ask for budgets. The line producer will call me and ask, "Can I get a budget for Prague?" I know they're calling the same bloody places: Vancouver, Budapest, London. There's so much game playing that happens. Good executives know if the line producer is comparing apples to apples. Notso-good ones get fooled. There's a lot of speculation involved that goes into creating and delivering a budget. Line producers can make the numbers do whatever they want.

\section{Explain the speculation.}

There are so many unknown variables when you're budgeting a movie, especially at the point when you're doing a budget just based on the script. Are we building that set or is it a location shoot? When the script says, "They walk into a bar," what is the size of that bar? Is it a little bar? A big bar? I can put \$1 million in the construction budget, and get a lot with that in Prague and Budapest. Can I keep the budget the same if I'm the line producer who is comparing Vancouver? Sure, but it won't go nearly as far. You can goose each of those items to hit the overall budget number you want.

You can do it in other ways, too. How many foreign crew do you need to bring? I always argue that you don't have to bring many people with you if you shoot in Prague, but if a line producer decides to ignore my advice and budget for ten more people in Prague than, say, Berlin because he or she simply wants to go to Berlin, then that will cost you salaries, hotels, per diem, drivers, and assistants. Prague suddenly costs more. There are so many variables.

But if a line producer pitches Berlin at, say, $\$ 47$ million, isn't there a risk that it will end up costing $\$ 55$ million?

Yes, and that happens. I'm conservative because I don't want to get egg on my face. I don't want to keep dropping costs and dropping costs to get the job only to discover that it can't be done for what I've quoted. Look, if you do ten budgets, you're lucky to get one movie. What if you get the one with the unrealistic budget? Then you're screwed because you faked the numbers. 
How has business changed in the last five years?

Prague went from more than $\$ 1$ billion per year in film spend-just from larger Hollywood and British features, excluding smaller, foreign coproductions-to less than \$200 million. We started pressing in earnest for incentives around 2006 and 2007. I remember taking the producer Mark Johnson and Andrew Adamson, who directed the first two Shrek movies $(2001,2004)$ and the first two The Chronicles of Narnia movies $(2005,2008)$, to meet with a government minister about incentives. Adamson is responsible for earning the studios billions in revenues with those films alone. Johnson has won an Oscar and an Emmy. I introduce Johnson and Adamson, including the films they've done, and the minister says to Andrew in the most condescending tone you can imagine, "So-you make fairy tales." Meanwhile, in London, the prime minister sends an RAF helicopter to fly Steven Spielberg from the airport to 10 Downing Street for lunch.

\section{How do you account for the difference in perspective?}

It's different cultural histories. England has always had a relationship, a love affair, with Hollywood. There are some obvious affinities there, language and culture being the most obvious, but also a serious appreciation of the economic impact of filmmaking. Sure, there's a rich history of Czech filmmaking, but Hollywood is more of a secondhand culture; it's just not Czech. Sure, they love Spielberg. Sure, they love Ridley Scott. But the whole creative industries rhetoric hasn't taken a firm hold here yet, especially when you compare it to places like England where there's a real determination to value the economic and cultural impact of information technology, knowledge workers, and cultural production. It's valued more than industrial production. The history here is very different.

\section{What's your pitch in those meetings with government ministers?}

We pitch economic multipliers, direct and indirect employment opportunities, growth in the service sector, and so on. But the problem here is that the politicians don't care about the public. They care about themselves. They want to know what's in it for them. It's a corrupt, narcissistic system-such an old, antiquated style of government and accountability. Unless you can explain what's in it for them, they don't appreciate it. Sure, in America and England there's corruption and selfish politicians, but the implicit rules are different. They know they are still held accountable for helping to grease the economic engine, and jobs are hugely important. That's how you get reelected. Jobs. "I created jobs." And that simply doesn't exist here. It's hard to make that pitch and have it stick. Politicians here 
don't believe the data. They don't believe the argument that for every dollar you spend, you get two or three dollars back in tax benefits down the road.

But we were persistent. We made those arguments over and over again and eventually, in 2010, we finally got a very, very modest incentive approved.

It was announced with great fanfare.

Of course, but it ultimately has had a disastrous effect on production over the past three years.

\section{Tell us more.}

Our intention from the start was to establish an incentive that would support major features. If you're shooting a \$2 million Polish, Czech, Italian coproduction, you're not creating substantial economic impact. However, if you're shooting a $\$ 100$ million blockbuster, you will create value for the city. From day one, our objective was to get those movies that generate lots of money. Perversely, the incentive program has done the exact opposite of what it was intended to do. It doesn't bring big movies at all. It brings the small European coproductions.

Why? Because it's been a flawed, poorly structured program from the very start. There's simply not enough money in the program-it's capped-and until very recently, it was distributed on a first-come, first-served basis.

\section{Can you elaborate on those flaws?}

Originally, I'm sure first-come, first-served seemed like the fairest approach, but the process wasn't structured correctly. Producers applied for the incentive before their movies were even green-lit for production. There was no mechanism to protect against that, and when the projects never materialized, there was no mechanism to release the funds back into the program until it was too late. The process tied up the fund's resources and reduced what was available to other producers, especially if they were shooting anything bigger than a $\$ 5$ or $\$ 10$ million movie.

\section{Damn.}

Exactly. It's been highly effective at alienating Hollywood and pissing off producers. We invite them to the city, they make the trip, and we show them around, and when it comes time to make the decision, it's, "Oh, the fund's depleted." There also was a real risk of people getting screwed. There was money in the program when they applied, if they were lucky, and maybe it was still there when their application came up for review. What if they were betting on that incentive? It never 
happened, fortunately. But we used to make four or five movies a year and now we're happy when we make two, and usually we're making only one. So the program has driven away the very business it was intended to attract.

Can you describe the effects of the most recent change to the incentive program?

It's made it even worse. Instead of being first-come, first-served, they open up a window during which they accept applications for the incentive. Everyone applies within this window. Then the government reviews the projects and prorates the approved applications against the available funds. So, while we advertise a 20 percent incentive program, you can end up with a rebate worth 7 percent because you applied in a year with too many projects. If you're expecting 20 percent, and you receive 7 percent, you get pissed off.

But that's the new reality this year and, in theory, going forward, unless we successfully lobby for more money. Really, that's my job these days. I now spend more than half my time dealing with rebate-related issues. It's no longer just about film production. I've become more of a lawyer and an accountant and a lobbyist. I spend so much time trying to understand how this whole process works from a legal perspective, from a financial perspective, from a policy perspective, and from a bureaucratic perspective. I spend time trying to figure out how to game it and goose it to secure work from foreign producers. I need to convince the government to support the film business. I need to figure out how to keep from losing business to other countries. All of this, instead of focusing on the production itself.

This is interesting. It clearly shows that no two incentives are the same, and that navigating them around the world can feel a bit like working your way through a labyrinth. It also illustrates how incentives structure production. In this case, the changes to the incentive affected the types of productions coming to town and the nature of your work.

We used to be the number one company in Prague. If you look at the Hollywood films made here before 2010, we handled most of them. Now? Those movies are going away. Instead we have small European movies, like the Danish film A Royal Affair (2012), or low-budget television series like The Musketeers (2014-ongoing). I'm American, so all of my contacts and relationships are in Hollywood with the networks and studios and their related partners in London. I put all my cookies in that basket. The way Prague business works-and this is true in most countries in the service business-is that you have a Russian guy who has a company here and services all the Russian movies, and a French guy services the French movies, because it's cultural. They speak the same language. 
I did a movie with a French group once and I didn't understand the rules. It was a completely different system. I tried to do a Bollywood movie that came here once and it was like: no, thank you. I did not want to be involved in that crazy process. It was just so alien!

The companies here with their toes in the European coproduction world or the Danish production world have seen their business improve, because they can service three or four projects in a year that need a few hundred thousand dollars in rebate money. I need \$10 million. A few years ago, World War Z (2013) and Hercules (2014) would have filmed in Prague, but instead they filmed in Budapest. It's hurt our business disproportionately when compared to the smaller companies here, or to similar companies in other cities with more competitive incentives. When you see articles here in the paper, you see people like me and others, whose business depends on Hollywood, bitching and moaning, but you don't see anybody bitching and moaning from those other companies. That's just how it is.

\section{How has this affected your pitch to producers?}

It's a dangerous game. My business is based on my reputation, and that's exactly what's at stake here. If you listened to the Ministry of Culture when they announced the incentive changes at Cannes this year, you'd think heaven had arrived in Prague. There were a bunch of interviews and press releases, blah, blah, blah. But I'm the one who deals directly with those studio executives. I'm the one they get pissed at. I get screwed, not some idiot in the government. I just have to be honest, more honest than people in the government or the Film Commission.

The main way we've responded to the situation is that we've opened an office in Budapest. Now I spend a good deal of my time selling Budapest and going to Budapest and working in Budapest. That's an easy sell. There's more competition in Budapest, more firms, and we weren't the first firm there. But there's so much production going to the city that there is enough work for everybody.

Ten years ago, I would do a budget for three or four movies and get one of them. Now, I do budgets for ten or fifteen movies, and get one of them. It's much more research and development and comparison work than it used to be.

\section{How is Budapest different from Prague?}

Budapest is more logistically challenging. It's a bigger city. It's busier, more crowded, harder to park. There are greater distances between locations. Yet there are more location choices because it is bigger. So creatively it can be more interesting. It also has more studios. A good tax credit brings investment, so they have built a lot of stages. It's become a major destination. 
What other locations have potential to emerge as competitive production hubs?

I don't anticipate much change in the go-to locations in Europe. London is the first stop for big movies. Berlin has good incentives, studios, and locations. Prague and Budapest will remain strong as long as the incentives stay. They have the infrastructure, locations, and skill base.

Beyond that, I think Serbia is a place to watch. It has the lowest labor costs in Europe right now. It's also very welcoming. It's mainly because of one lady who left Serbia years ago to work in Los Angeles and then went back to open a service company. She took her knowledge of the business and started building up a really user-friendly base there. It just lacks location variation because it's been bombed and destroyed over the years. But there's a new studio. They're even getting an incentive. It'll never become Budapest or Prague. It's not big enough. Still, I'd rather go to Serbia than Bulgaria.

\section{Why is that?}

Bulgaria is a weird place. It's not just that it's corrupt. It's also this strange mash-up that results from out-of-control Western capitalism descending on a former Communist country full of a very poor, screwed-over population. And there are no good production partners there to help you navigate it. And then there's Romania. It should be a preeminent place that steals work from Budapest and Prague. The crew there is great. But it needs an incentive. And it needs new service companies that work in a transparent, cooperative way instead of ripping off their supposed partners.

Croatia is also great, but it will never be anything more than the place you go for two weeks when you need that beautiful location on the seaside. There's no reason to be based in Croatia. It's more expensive, and there's not much infrastructure. Instead, productions keep their bases in Budapest or Prague.

I don't expect anything from Ukraine or Poland. It's also too late for Slovakia. France has an incentive but it's not going to suddenly bring tons of work to France. People only go to France if the script requires it. It's the same with Italy.

Fifteen years ago it was a different story. There was some urgency to the question, "What location is next?" Not anymore. Now the globe is small. Everybody knows everywhere. The map is set, so to speak.

\section{What about outside of Europe?}

It's the same. It's already easier somewhere else. I don't expect a mad rush to Brazil, for example, even if they offered an incentive. Or Africa. If you go to Africa, you go to South Africa. Nowhere else. Dubai and Abu Dhabi want to get in the game. They're investing millions and millions of dollars. They will get the one or two odd movies that need the Middle East visual backdrop. Still, a lot of international 
television or regional films are shooting there because the finance is there. There is a massive film and TV industry in the region with nothing to do with Hollywood, and that is important business if you can meet their needs.

Asia is more interesting because the locations are more diverse. China is eager to invest money into production. But service-wise, the map is pretty established. It's China and Thailand. Malaysia hopes to siphon some of that interest. Maybe they will. Japan is too expensive-no one shoots there. I think South Korea is interesting. It's so cheap. It has amazing locations. It's untapped right now. If I started over, I'd look at South Korea.

\section{What about Los Angeles?}

It's still the center of film and television production, but the career opportunities are not there anymore. Maybe new tax incentives will change that. I graduated from film school in 1989. I could do whatever I wanted. It was an open-door policy for anyone who was eager and willing to work hard. I started in Portland before it unionized. I did fifteen movies there in less than three years. It was a TV movie factory-just one after another. I moved to L.A., and there was a ton of production happening there, too. It's not like that anymore. I wouldn't recommend this business to any young person in the States. It's not secure. There's just a general unease about the number of movies being made today, how long that trajectory will continue, and what kinds of movies Hollywood will make in the future. Right now, everyone seems to think we will end up with a dozen $\$ 300$ million blockbuster movies each year and the rest will end up on your cable box or iTunes. You won't go to the cinema anymore. And that affects labor. What are they going to pay you to work on a film that ends up on a cable box? Not what they pay you to work on Mission Impossible. And those movies aren't being made in Los Angeles.

Maybe in New Orleans or Atlanta it feels like glory days. It certainly does in Budapest. But not in Los Angeles. 